\title{
REVIEWS
} Augusto Orlandi ${ }^{1, D-E}$

\section{Adipose Tissue-Derived Stem Cell Therapy for Post-Surgical Breast Reconstruction - More Light than Shadows ${ }^{\star}$}

1 Department of Biomedicine and Prevention, Anatomic Pathology, University of Rome Tor Vergata, Italy

2 Department of Biomedicine and Prevention, Plastic Surgery, University of Rome Tor Vergata, Italy

A - research concept and design; $\mathbf{B}$ - collection and/or assembly of data; $\mathbf{C}$ - data analysis and interpretation;

$\mathbf{D}$ - writing the article; $\mathbf{E}$ - critical revision of the article; $\mathbf{F}$ - final approval of article; $\mathbf{G}$ - other

\begin{abstract}
Breast cancer remains the most common tumor in women, and new techniques for post- surgical breast reconstruction have been recently introduced. These new procedures include autologous fat grafting with or without the enrichment with autologous stromal vascular fraction (SVF), platelet-derived growth factors and insulin. The reported improvement of fat graft viability with these techniques likely depends on the presence in the SVF of multipotent resident adipose derived-stem cells (ASCs). The clinical advantage derives from the plasticity of ASCs and their ability to generate new functional adipose tissue and vessels. However, there is an ongoing debate regarding the possible interplay between breast tumor cells and resident or transplanted ASCs for their capacity to locally secrete growth factors. Most of the data in the literature concerning ASCs is derived from in vitro models, whereas the knowledge of ASC behavior in vivo remains scarce. Recent reports concerning SVF/ASC enrichment of fat graft did not describe any significant worsening of prognosis for patients undergoing those procedures. However, further studies and longer follow-ups are needed to specifically define technical procedures and to confirm the safety of procedures of SVF/ASC enrichment during post-surgical breast reconstruction (Adv Clin Exp Med 2015, $24,3,545-548)$.
\end{abstract}

Key words: ASCs, breast reconstruction, fat grafting, SVF.

Breast cancer remains the most common tumor in women but the scars and deformities following its surgical removal could give rise to psychological problems [1]. Recently, plastic surgery procedures for the treatment of deformities following breast cancer or tissue defects include autologous fat grafting with or without the enrichment with enzimatically-obtained stromal vascular fraction (SVF), platelet-derived growth factors and hormones including insulin $[2,3]$. Ameliorated transplanted fat viability is critically regulated by the presence of resident adipose derived-stem cells (ASCs). The latter can be isolated by cultures of the enzymatically-obtained SVF from aspirate subcutaneous adipose tissue [4]. ASCs displays a capacity of differentiation similar to bone marrow mesenchymal stem cells (MSCs) and showed in vivo the expression of stem cell markers, such as CD44 (Fig. 1) [5]. ASCs are readily responsive to platelet-derived growth factors and insulin, through the activation of complex receptor-mediated pathways stimulating proliferation and differentiation [6]. Several studies reported that the use of autologous fat graft, enriched with SVF, increases the viability of the fat graft, likely due to the creation of new blood vessels and the promotion of cell turn-over [7, 8]. SVF/ASCs, because of their ability to differentiate into various cell lineages

\footnotetext{
* This work was partially supported by a 2012 grant from Transplantation Agency of Lazio, Rome.
} 
apart from adipocytes, have been proposed to increase autologous fat graft viability for regenerative purpose [4]. More recently, in a randomized placebo-controlled trial, the enrichment with ex vivo expanded ASCs improved fat graft viability, so opening new prospective to their selective use in reconstructive surgery [9]. Unfortunately, the safety of the procedure of stem cells enrichment remains unclear in the field of reconstructive surgery after mastectomy, where the full clinical potential of ASCs needs deeper investigation.

\section{Adipose Derived Stem Cells and Breast Cancer Progression}

Recent studies demonstrated the increase of efficacy of autologous fat grafting when associated to SVF enrichment, in particular in the treatment of lower extremity ulcers [10]. In response to damage or ischemia, circulating and resident stem cells promote angiogenesis through secretion of growth factor, such as VEGF, while collagen synthesis contributes to tissue remodelling following acute and chronic damages [11-13]. Actually, major attention has been focused in order to clarify if the transfer of ASCs-containing SVF may increase the risk of breast cancer development or relapse [14]. Tumor microenvironment consists in a complex signaling network which influences the behavior of both resident stem cells and tumor cells [15]. Angiogenesis is one of the crucial events for cancer development and growth, and VEGF secretion plays a pivotal role in this process, thereby becoming a main target for antitumor strategies $[16,17]$. ASCs may contribute to stromal support for cancer cells by the local delivering of inflammatory cytokines and/or growth factors including VEGF, thus facilitating the recruitment of migratory cancer cells, tumor growth and metastasis [18]. In fact, a large number of myofibroblasts is present in the stromal compartment of invasive breast cancer [19-21] and SVF-derived ASCs express high levels of alpha-smooth muscle actin, a myofibroblastic marker also expressed from mesenchymal tumor cells [22]. Similarly to circulatory stem cells, resident or seeded ASCs may favor cancer growth by supporting myofibroblast differentiation, the formation of new vessels, the synthesis or deposition of extracellular matrix and the release of metalloproteinases responsible of extracellular matrix remodeling [23-26]. Recent data suggests that soluble factors secreted from breast cancer cells inhibit adipogenic differentiation and increase the proliferation, pro-angiogenic factor secretion and myofibroblastic differentiation of ASCs [27-29]. A stable population of engrafted stem cells may contribute to a inflammatory/growth factor-driven of residual breast cancer cells, a potential risk parallel to the aesthetic advantage $[29,30]$. Nevertheless, the role of resident or engrafted stem cells in breast cancer progression is still controversial. Several studies document that ASCs influence variably the growth of active and dormant cancer cells [31]. ASCs transplantation or co-injection into mouse breast cancer models had an inhibitory
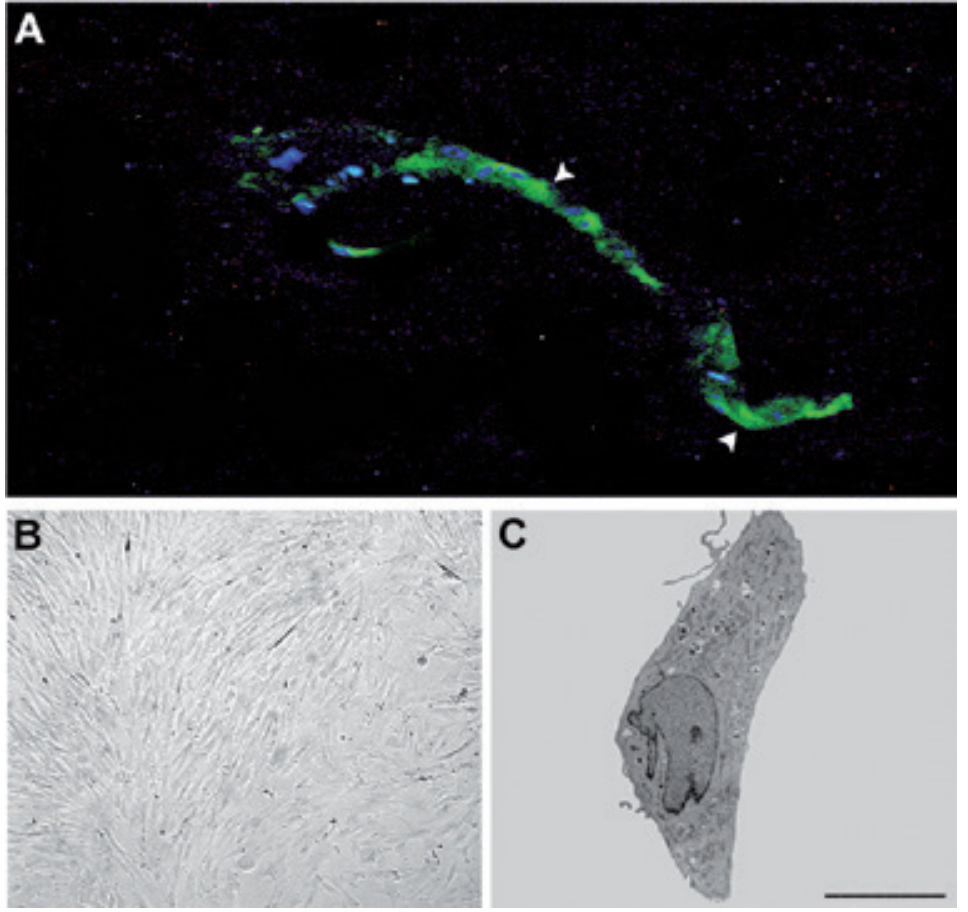

Fig. 1. Morphology and stem phenotype of adipose-derived stem cells in vivo and in vitro.

A) Immunofluorescence staining reveals the strong expression of CD44 stromal stem cell marker in the perivascular cells of in vivo breast adipose tissue (arrow heads, green fluorescence). Hoechst nuclear are staining. Scale bar, $100 \mu \mathrm{m}$.

B) Phase contrast micrograph shows the typical elongated shape of adipose-derived stem cells cultured in the presence of $10 \%$ FBS. Original magnification, X200.

C) Transmission electron microscopy displays the ultrastructural appearance of an adipose tissue-derived stem cell cultured in vitro in presence of serum, with rare intracytoplasmic lipid droplets accumulation. Scale bar, $10 \mu \mathrm{m}$ 
effect on tumor growth, likely due to the activity of ASC-dependent Poly ADP ribose polymerase cleavage inducing cancer cell apoptosis [32]. Nevertheless, many receptor-mediated pathways involved in breast cancer growth, including those related to ErbB, FGFR and EGFR, are also involved in adipogenic differentiation of ASCs [4]. This is why further studies are needed to clarify how growth factors and cytokines differently stimulate resident stem and cancer cells and to can address cancer cell differentiation without stimulatory proliferation.
In conclusion, follow-up studies did not prove any significant difference in relapse when patients treated with fat grafting were compared with untreated ones, so at least for the presence of resident ASCs, fat grafting in post-surgical breast reconstruction appears safe. However, in relation to reconstructive therapy utilizing fat graft enrichment with SVF or expanded ASCs, further studies with optimization of preclinical procedures and longer follow-up are required; at the present, the literature suggests that SVF/ASC enrichment should be postponed until there is no evidence of active disease.

Acknowledgement. We thank Dr S. Cappelli for technical assistance.

\section{References}

[1] Bostwick J $3^{\text {rd}}$ : Breast reconstruction following mastectomy. CA Cancer J Clin 1995, 45, 289-304.

[2] Missana MC, Laurent I, Barreau L, Balleyguier C: Autologous fat transfer in reconstructive breast surgery: indications, technique and results. Eur J Surg Oncol 2007, 33, 685-690.

[3] Weichman KE, Broer PN, Tanna N, Wilson SC, Allan A, Levine JP, Ahn C, Choi M, Karp NS, Allen R: The role of autologous fat grafting in secondary microsurgical breast reconstruction. Ann Plast Surg 2013, 71, $24-30$.

[4] Cervelli V, Gentile P, Scioli MG, Grimaldi M, Casciani CU, Spagnoli LG: Application of platelet-rich plasma in plastic surgery: clinical and in vitro evaluation. Tissue Eng Part C Methods 2009, 15, 625-634.

[5] Mitchell JB, McIntosh K, Zvonic S, Garrett S, Floyd ZE, Kloster A: Immunophenotype of human adipose-derived cells: Temporal changes in stromal-associated and stem cell-associated markers. Stem Cells 2006, 24, 376-385.

[6] Cervelli V, Scioli MG, Gentile P, Doldo E, Bonanno E, Spagnoli LG: Platelet-rich plasma greatly potentiates insulin-induced adipogenic differentiation of human adipose-derived stem cells through a serine/threonine kinase Akt-dependent mechanism and promotes clinical fat graft maintenance. Stem Cells Transl Med 2012, 1, $206-220$.

[7] Gentile P, Orlandi A, Scioli MG, Di Pasquali C, Bocchini I, Curcio CB: Comparative translational study: the combined use of enhanced stromal vascular fraction and platelet-rich plasma improves fat grafting maintenance in breast reconstruction. Stem Cells Transl Med 2012, 1, 341-351.

[8] Gentile P, Di Pasquali C, Bocchini I, Floris M, Eleonora T, Fiaschetti V, Floris R, Cervelli V: Breast reconstruction with autologous fat graft mixed with platelet-rich plasma. Surg Innov 2013, 20, 370-376.

[9] Kolle SF, Fischer-Nielsen A, Mathiasen AB, Elberg JJ, Oliveri, RS, Glovinski PV: Enrichment of autologous fat grafts with ex-vivo expanded adipose tissue-derived stem cells for graft survival: a randomised placebo-controlled trial. Lancet 2013, 382, 1113-1120.

[10] Cervelli V, Gentile P, De Angelis B, Calabrese C, Di Stefani A, Scioli MG: Application of enhanced stromal vascular fraction and fat grafting mixed with PRP in post-traumatic lower extremity ulcers. Stem Cell Res 2011, $6,103-111$.

[11] Orlandi A, Bennett M: Progenitor cell-derived smooth muscle cells in vascular disease. Biochem Pharmacol 2010, $79,1706-1713$.

[12] Ferlosio A, Arcuri G, Doldo E, Scioli MG, De Falco S, Spagnoli LG: Age related increase of stem marker expression influences vascular smooth muscle cell properties. Atherosclerosis 2012, 224, 51-57.

[13] Stasi MA, Scioli MG, Arcuri G, Mattera GG, Lombardo K, Marcellini M, Riccioni T, De Falco S, Pisano C, Spagnoli LG, Borsini F, Orlandi A: Propionyl-L-carnitine improves postischemic blood flow recovery and arteriogenetic revascularization and reduces endothelial NADPH-oxidase 4-mediated superoxide production. Arterioscler Thromb Vasc Biol 2010, 30, 426-435.

[14] Rietjens M, De Lorenzi F, Rossetto F, Brenelli F, Manconi A, Martella S: Safety of fat grafting in secondary breast reconstruction after cancer. J Plast Reconstr Aesthet Surg 2011, 64, 477-483.

[15] Kucerova L, Skolekova S, Matuskova M, Bohac M, Kozovska Z: Altered features and increased chemosensitivity of human breast cancer cells mediated by adipose tissue-derived mesenchymal stromal cells. BMC Cancer 2013, 13, 535 .

[16] Cassinelli G, Zuco V, Petrangolini G, De Cesare M, Tortoreto M, Lanzi C: The curative efficacy of namitecan (ST1968) in preclinical models of pediatric sarcoma is associated with antiangiogenic effects. Biochem Pharmacol 2012, 84, 163-171.

[17] Tarallo V, Vesci L, Capasso O, Esposito MT, Riccioni T, Pastore L, Orlandi A, Pisano C, De Falco S: A placental growth factor variant unable to recognize vascular endothelial growth factor (VEGF) receptor-1 inhibits VEGFdependent tumor angiogenesis via heterodimerization. Cancer Res 2010, 70, 3413.

[18] Gehmert S, Gehmert S, Prantl L, Vykoukal J, Alt E, Song YH: Breast cancer cells attract the migration of adipose tissue-derived stem cells via the PDGF-BB/PDGFR-b signaling pathway. Biochem Bioph Res Co 2010, 398, 601-605. 
[19] Orimo A, Gupta PB, Sgroi DC, Arenzana-Seisdedos F, Delaunay T, Naeem R: Stromal Fibroblasts Present in Invasive Human Breast Carcinomas Promote Tumor Growth and Angiogenesis through Elevated SDF-1/CXCL12 Secretion. Cell 2005, 121, 335-348.

[20] Orlandi A, Bochaton-Piallat ML, Gabbiani G, Spagnoli LG: Aging, smooth muscle cells and vascular pathobiology: implications for atherosclerosis. Atherosclerosis 2006, 188, 221-230.

[21] De Wever O, Demetter P, Mareel M, Bracke M: Stromal myofibroblasts are drivers of invasive cancer growth. Int J Cancer 2008, 123, 2229-2238.

[22] Orlandi A, Bianchi L, Spagnoli LG: Myxoid dermatofibrosarcoma protuberans: morphological, ultrastructural and immunohistochemical features. J Cutan Pathol 199825, 386-393.

[23] Muehlberg FL, Song YH, Alexander K, Pinilla SP, Droll LH, Leng X: Tissue-resident stem cells promote breast cancer growth and metastasis. Carcinogenesis 2009, 30, 589-597.

[24] Wang YY, Lehuédé C, Laurent V, Dirat B, Dauvillier S, Bochet L: Adipose tissue and breast epithelial cells: a dangerous dynamic duo in breast cancer. Cancer Lett 2012, 324,142-151.

[25] Chandler EM, Seo BR, Califano JP, Andresen Eguiluz RC, Lee JS, Yoon CJ: Implanted adipose progenitor cells as physicochemical regulators of breast cancer. Proc Natl Acad Sci 2012, 109, 9786-9791.

[26] Orlandi A, Ciucci A, Ferlosio A, Pellegrino A, Chiariello L, Spagnoli LG: Increased expression and activity of matrix metalloproteinases characterize embolic cardiac myxomas. Am J Pathol 2005, 166, 1619-1628.

[27] Park TS, Donnenberg VS, Donnenberg AD, Zambidis ET, Zimmerlin L: Dynamic interaction between cancer stem cells and their stromal patners. Curr Pathobiol Rep 2014, 2, 42-52.

[28] Dirat B, Bochet L, Dabek M, Daviaud D, Dauvillier S, Majed B: Cancer-associated adipocytes exhibit an activated phenotype and contribute to breast cancer invasion. Cancer Res 2011, 71, 2455-2465.

[29] Karnoub AE, Dash AB, Vo AP, Sullivan A, Brooks MW, Bell GW: Mesenchymal stem cells within tumour stroma promote breast cancer metastasis. Nature 2007, 449, 557-563.

[30] Pinilla S, Alt E, Abdul Khalek FJ, Jotzu C, Muehlberg F, Beckmann C: Tissue resident stem cells produce CCL5 under the influence of cancer cells and thereby promote breast cancer cell invasion. Cancer Letters 2009, 284, $80-85$.

[31] Zimmerlin L, Donnenberg AD, Rubin JP, Basse P, Landreneau RJ, Donnenberg VS: Regenerative therapy and cancer: in vitro and in vivo studies of the interaction between adipose-derived stem cells and breast cancer cells from clinical isolates. Tissue Eng, Part A 2011, 17, 93-106.

[32] Sun B, Roh KH, Park JR, Lee SR, Park SB, Jung JW: Therapeutic potential of mesenchymal stromal cells in a mouse breast cancer metastasis model. Cytotherapy 2009, 11, 289-298.

\title{
Address for correspondence:
}

\author{
Augusto Orlandi \\ Institute of Anatomic Pathology \\ Department of Biomedicine and Prevention \\ Tor Vergata University of Rome \\ Via Montpellier \\ 00133 Rome \\ Italy \\ Tel.: +390620903957 \\ E-mail: orlandi@uniroma2.it \\ Conflict of interest: None declared
}

Received: 3.03.2014

Revised: 15.12.2014

Accepted: 18.12.2014 